\title{
O USO DO DISCLOSURE NARRATIVO EM RELATÓRIOS ANUAIS CORPORATIVOS PARA INFERÊNCIA DA CONTINUIDADE DAS EMPRESAS
}

\section{THE USE OF ANNUAL REPORTS NARRATIVE DISCLOSURES TO PREDICT THE FIRM'S FINANCIAL RISK OF BANKRUPTCY}

\author{
MARCELO SANCHES PAGLIARUSSI \\ Doutor em Ciência e Engenharia dos Materiais pela \\ Universidade Federal de São Carlos \\ Professor Assistente da Fundação Instituto Capixaba de \\ Pesquisa em Contabilidade, Economia e Finanças \\ Vitória/ES, Brasil \\ E-mail: marcelo@fucape.br
}

\author{
RENATO SCOTÁ \\ Graduado em Contabilidade pela \\ Faculdade de Ciências Econômicas de Colatina \\ Mestrando em Ciências Contábeis pela Fundação Instituto \\ Capixaba de Pesquisa em Contabilidade, Economia e Finanças \\ Vitória/ES, Brasil \\ E-mail: renato.scota@caixa.gov.br
}

\section{Resumo}

Este trabalho buscou verificar se é possível prever a descontinuidade empresarial com base nas informações contidas nas seções narrativas dos relatórios anuais corporativos. Para tanto, foram aplicados, em um conjunto de empresas brasileiras listadas na BOVESPA, os modelos desenvolvidos por Smith e Taffler (2000). Uma amostra de relatórios anuais de empresas falidas e não falidas de setores e portes semelhantes foi levantada. Na amostra buscaram-se os relatórios anuais do último exercício anterior à concordata ou falência relativa às empresas falidas e estas foram emparelhadas com empresas financeiramente saudáveis. Os relatórios anuais foram submetidos a um procedimento de análise de conteúdo idêntico ao realizado por Smith e Taffler (2000). Após a análise de conteúdo, foram calculados e analisados os scores obtidos pelas empresas listadas na BOVESPA e verificou-se se o poder de classificação destes modelos foi estatisticamente significante. Concluiu-se que os modelos desenvolvidos por Smith e Taffler (2000), apesar de terem sido desenvolvidos em um contexto institucional bastante diferente do Brasil, ao serem aplicados nesta amostra, apresentaram poder de classificação de empresas falidas e não falidas estatisticamente significante. Os resultados apontam que o disclosure narrativo apresentado nos relatórios anuais corporativos constitui uma importante fonte de informação para a análise da continuidade das empresas.

Palavras-chave: relatórios anuais corporativos; análise de conteúdo; desempenho financeiro; qualidade do disclosure.

\section{Abstract}

In this work we aimed to analyze the appropriateness of information presented at the narrative sections of corporate annual reports as predictors of a firm's discontinuity. We gathered a sample of corporate annual reports from companies listed at BOVESPA and then we applied two models developed by Smith and Taffler (2000). The sample was composed by failed and successful firms, matched by industry and firm size. For the failed firms, we collected the last annual report before the bankruptcy. Annual reports were content analyzed through a procedure developed by Smith and Taffler (2000). Subsequently, we determined the scores for each firm using Smith and Taffler's (2000) models and analyzed the discriminating power of each model. Results pointed out that Smith and Taffler's (2000) models, even though being developed in a different institutional setting, provided a significant discriminating power between failed and non failed firms. This result suggests that the narrative disclosure in annual reports is an useful source of information related to firms continuity.

Key words: corporate annual reports, content analysis, financial performance, disclosure quality. 


\section{INTRODUÇÃO}

Este estudo tem por objetivo verificar a aplicabilidade de dois modelos desenvolvidos para empresas listadas na Bolsa de Valores de Londres em uma amostra composta por empresas listadas na Bolsa de Valores de São Paulo.

Ao aplicar esses modelos no Brasil, será possível verificar se a descontinuidade das empresas pode ser prevista por meio de modelos que utilizem apenas as informações apresentadas nas seções narrativas dos relatórios da administração.

O fenômeno da descontinuidade empresarial tem sido abordado principalmente com a utilização dos números contábeis apresentados nos relatórios anuais como base de dados, como em Beaver (1966), Altman (1968), Matias e Siqueira (1996), Rocha (1999), Lennox (1999) e Minuzzi (2001).

Neste trabalho não serão utilizados os números contábeis, mas apenas o disclosure narrativo apresentado nos Relatórios da Administração como instrumento de inferência para tentar prever o risco financeiro de falência das empresas, aplicando os modelos desenvolvidos por Smith e Taffler (2000).

No Brasil, a publicação dos relatórios da administração é exigida para todas as sociedades anônimas de capital aberto, de acordo com a lei $6.404 / 76$, sendo que o maior usuário de suas informações, para Lopes (2002, p. 7), é o mercado financeiro, que se transforma em "laboratório" para o teste do papel da contabilidade e de como essas informações interagem com o próprio mercado.

Os relatórios da administração possuem duas partes: demonstrações financeiras e seções narrativas. Vários autores, como Balata e Breton (2005), já levantaram dúvidas sobre a harmonia das duas partes. As demonstrações financeiras das sociedades anônimas de capital aberto são auditadas e, então, submetidas a uma forma de controle. As seções narrativas não são controladas, segundo Balata e Breton (2005), abrindo espaço para manipulação. Os usuários, dessa forma, estão potencialmente expostos a mensagens contraditórias que produzem um efeito de dissonância.

No Brasil, de acordo com a Instrução CVM 308 (Artigo 25), os auditores têm o dever de verificar se as informações divulgadas no relatório da administração estão em consonância com as demonstrações auditadas.

Comparando as duas seções dos relatórios contábeis, os demonstrativos financeiros e as seções narrativas, Smith e Taffler (1992) relataram uma ligação entre desempenho da firma e sua clareza nas seções narrativas: empresas com desempenho ruim tendem a apresentar as seções narrativas mais obscuras e confusas.

Hildebrandt e Snyder (1981) concluem em seu trabalho que independente do desempenho financeiro da firma, a linguagem no relatório anual será predominantemente positiva. O que não diverge dos achados de Smith e Taffler (1992), já que o discurso positivo da narrativa tem sido proposto como tentativa de ofuscar o desempenho ruim.

Um dos interesses dos usuários desses relatórios contábeis, como o mercado financeiro, é quebrar, ao menos em parte, a assimetria informacional com diversas possibilidades: prevendo tanto o desempenho futuro da firma como seu risco de descontinuidade, dentre outros.

Existem vários trabalhos que desenvolveram modelos para prever a descontinuidade da firma utilizando os números contábeis, com índices de acerto superiores a $90 \%$. Também existem estudos, como o de Smith e Taffler (1992), de Balata e Breton (2005), dentre 
outros, que apontam a relação entre os números contábeis e as seções narrativas apresentadas nos relatórios anuais corporativos.

Considerando a relação entre o desempenho das empresas e o texto do relatório anual, Smith e Taffler (2000) desenvolveram modelos que foram capazes de prever, com índices de acerto superiores a 95\%, a descontinuidade das empresas, analisando apenas as características textuais de tais relatórios, utilizando uma amostra de empresas listadas na Bolsa de Valores de Londres.

Este trabalho aplicará os modelos de Smith e Taffler (2000) em um ambiente completamente diferente do artigo desenvolvido por eles. Os modelos serão aplicados no mercado brasileiro, mais especificamente com empresas listadas na BOVESPA.

No Brasil, o governo emite todas as regras de contabilidade e os corpos profissionais não tinham nenhum poder de fato para influenciar os padrões (Lopes 2006), o que divergia dos padrões adotados nos EUA e pelo IASB.

Apenas recentemente, com a criação do Comitê de Pronunciamentos Contábeis, pela Resolução CFC $n^{\circ} \underline{1.055 / 05}$, os profissionais e órgãos contábeis passaram a ter certa influência na elaboração das normas técnicas ligadas à contabilidade.

O CPC tem como objetivo

o estudo, o preparo e a emissão de Pronunciamentos Técnicos sobre procedimentos de Contabilidade e a divulgação de informações dessa natureza, para permitir a emissão de normas pela entidade reguladora brasileira, visando à centralização e uniformização do seu processo de produção, levando sempre em conta a convergência da Contabilidade Brasileira aos padrões internacionais. (CPC, 2009, p.3)

Anteriormente ao CPC, a contabilidade brasileira poderia ser considerada como híbrida, já que contempla influências do modelo italiano e do americano (IUDÍCIBUS, 1997). Inicialmente havia preponderância da escola italiana no Brasil, porém, principalmente pelo aumento de empresas multinacionais, inclusive das empresas de auditoria, o modelo contábil brasileiro passou a sofrer influência e vem se adaptando às normas americanas (COSTA, 2005).

Estes fatores levaram a contabilidade brasileira a um modelo único, que atualmente se diferencia da escola italiana indo, aos poucos, se adequando ao IFRS.

Existem outras diferenças conjunturais entre o Brasil e a Inglaterra, como a forma da legislação (Common Law, na Inglaterra e Code Law, no Brasil), a concentração do controle acionário (muito maior no Brasil) e o próprio idioma.

O sistema jurídico dos países pode impactar na qualidade das informações contábeis. As empresas situadas em países Common Law refletem as más notícias mais rápido que empresas localizadas em países Code-Law (Bushman e Piotroski, 2005).

A justificativa desta pesquisa, além de verificar a aplicabilidade no Brasil dos modelos desenvolvidos por Smith e Taffler (2000), baseia-se na possibilidade de prever a falência da empresa utilizando apenas as seções narrativas dos relatórios anuais, o que influenciaria internamente as empresas na forma como são relatadas as informações nesses relatórios, possibilitando estudos mais aprofundados sobre os dados e a maneira como serão publicados.

Os resultados deste trabalho podem influenciar também o ambiente externo à corporação, já que seria mais uma ferramenta útil como modelo capaz de prever 
dificuldades financeiras e importante para ser empregada nas análises de crédito e de investimentos.

No campo científico, este estudo verifica se os achados de Bryan (1997), Abrahamson e Amir (1996) e Smith e Taffler (2000) quanto à associabilidade entre as seções narrativas e o futuro financeiro das firmas podem ser confirmados também no Brasil, já que existem diferenças conjunturais entre as nações que poderiam influenciar nos resultados: diferentes sistemas jurídicos podem inviabilizar o uso de um modelo articulado em uma nação em outra, pois conforme Bushman e Piotroski (2005) empresas localizadas em países que adotam o sistema commom law refletem em seus demonstrativos as más notícias mais rapidamente que empresas localizadas em países code Law; o idioma, também, pode interferir diretamente e de forma negativa nos resultados da aplicação dos modelos, tendo em vista que estes modelos se baseiam na análise do relatório anual e foram construídos levando-se em consideração o idioma inglês, de origem saxônica, que possui diferenças nas construções textuais em relação ao português, de origem latina.

Comparando os resultados de Abrahanson e Amir (1996) e Bryan (1997), somente as diferenças de regulação da publicação desses relatórios anuais corporativos não devem interferir significativamente nos resultados.

\section{ESTUDOS ANTERIORES}

Para Ball e Foster (1982), existe um vácuo no que diz respeito às teorias econômicas que sustentam pesquisas na área de dificuldade financeira, destacando que as técnicas de pesquisa como a análise de discriminante são amplamente utilizadas devido a essa situação.

Porém, ainda segundo Ball e Foster (1982), para validar os modelos estatísticos em um ambiente sem uma teoria consistente que explique pesquisas sobre falências, é necessário que o pesquisador tome bastante cuidado para que a pesquisa não se torne mais estatística do que contábil.

Com base na revisão realizada em seu trabalho, Ball e Foster (1982) concluem que além da inexistência de uma teoria suficientemente capaz de sustentar pesquisas sobre falências, ainda visualizaram que existe pouca tradição na literatura financeira sobre uma discussão detalhada de questões de validade interna.

Os primeiros estudos sobre previsão de falência identificados foram elaborados por volta da década de 1960, quando o assunto passou a ser mais pesquisado, devido à utilização de técnicas estatísticas. A próxima seção apresenta resumidamente os estudos a respeito de falências realizados no Brasil e no exterior.

\subsection{ESTUDOS REALIZADOS NO EXTERIOR}

Dentre os estudos que utilizam métodos estatísticos para tentar prever a falência das empresas, pode-se citar Beaver (1966), Altman (1968), Lennox (1999) dentre outros.

Para Beaver (1966), os indicadores mais importantes para a determinação do risco de falência são a geração de caixa/ dívida total, o lucro líquido/ ativo total, o exigível total/ ativo total, o capital de giro/ ativo total e a liquidez corrente. Utilizando esses índices, Beaver utilizou um teste de classificação dicotômica para prever a bancarrota das empresas. 
O estudo de Beaver (1968) também indica que evidências observadas nos cinco anos imediatamente anteriores à falência corroboraram a idéia de que a análise de indicadores poderia ser utilizada como fonte de informação para prever a descontinuidade das empresas.

Altman (1968) contrapôs-se à visão acadêmica que desprezava a análise baseada em índices contábeis. Na tentativa de testar a qualidade dos indicadores financeiros, o autor desenvolveu um estudo sobre a previsão de falência de empresas por meio da análise discriminante. Utilizando uma amostra de 66 firmas (33 solventes e 33 insolventes), estratificadas por setor e por tamanho, o autor testou 22 variáveis relacionadas à liquidez, rentabilidade, alavancagem, solvência e atividade. 0 modelo resultante desse estudo classificou corretamente como "falida", ou "não falida", 95\% das empresas da amostra.

Lennox (1999) examinou as causas da falência de companhias abertas inglesas, utilizando modelos logit, probit e de análise discriminante. Diferentemente de outros autores Lennox não emparelhou empresas falidas e não falidas em seu estudo, com o intuito de verificar os efeitos de tamanho e setor no risco da falência. A amostra utilizada nesse trabalho foi composta a partir dos dados existentes para 949 empresas britânicas (160 insolventes) ao longo do período 1987-1994. Seus resultados indicam que a lucratividade, alavancagem, fluxo de caixa, tamanho da companhia, setor da economia e ciclo econômico influenciam a probabilidade de falência.

Resumindo todas as pesquisas empíricas na área contábil, Ball e Foster (1982) mencionam que novas técnicas desenvolvidas por economistas e estatísticos são importantes na literatura empírica contábil.

Nesse mesmo estudo, Ball e Foster (1982) citam que os primeiros estudos multivariados utilizavam como técnica a Análise de Discriminante (como Altman 1968). Segundo Ball e Foster outros autores promoveram avanços nas formas de utilização de Análise de Discriminante e mais recentemente são utilizadas também outras técnicas como a utilização de regressões estatísticas.

Ball e Foster (1982) relatam ainda que apesar de serem importantes ferramentas para se validar pesquisas em contabilidade, existe o risco de o trabalho acabar contribuindo mais para as áreas econométricas e estatísticas do que para a literatura contábil.

\subsection{ESTUDOS REALIZADOS NO BRASIL}

No Brasil, os estudos realizados que tiveram como objetivo prever a falência também utilizam como fontes de informações os números apresentados nos relatórios contábeis, como Kanitz (1974), Matias e Siqueira (1996), Rocha (1999) e Minuzzi (2001).

Assim como Altman (1968), Kanitz (1974) desenvolveu seu modelo através da análise discriminante. A classificação utilizando seu modelo é feita através de uma escala desenvolvida por ele, a qual ele nomeou como termômetro de insolvência.

0 fator de insolvência calculado no modelo de Kanitz levava em consideração cinco variáveis, sendo $\circ \mathrm{X}_{1}=$ Lucro Líquido / Patrimônio Líquido, $\mathrm{X}_{2}=$ Ativo Circulante + Realizável a Longo Prazo / Exigível Total, $X_{3}=$ Ativo Circulante - Estoques / Passivo Circulante, $\mathrm{X}_{4}=$ Ativo Circulante $/$ Passivo Circulante, $\mathrm{X}_{5}=$ Exigível Total $/$ Patrimônio Líquido.

A equação do modelo de Kanitz era $\mathrm{FI}=0,05\left(\mathrm{X}_{1}\right)+1,65\left(\mathrm{X}_{2}\right)+3,55\left(\mathrm{X}_{3}\right)-1,06\left(\mathrm{X}_{4}\right)-$ $0,33\left(X_{5}\right)$.

Matias e Siqueira (1996) utilizaram regressão logística para tentar prever o risco de falência de bancos brasileiros. A amostra utilizada foi composta por 29 bancos que 
sofreram liquidação, intervenção ou incorporação no período compreendido entre julho de 1994 e abril de 1996, os autores propuseram um modelo a partir de um conjunto de 26 indicadores de desempenho econômico-financeiro. Esse modelo conseguiu classificar corretamente como falidos $91 \%$ dos bancos utilizados na amostra.

Em seu estudo, Rocha (1999) propôs um modelo de previsão de insolvência utilizando o Modelo de Risco Proporcional de COX. Esse modelo utilizou um conjunto de 26 indicadores financeiros e foi testado em uma amostra de 32 bancos (17 financeiramente saudáveis e 15 falidos), tal modelo fornece, segundo Rocha (1999), uma estimativa do tempo de sobrevivência, ou seja, o modelo fornece uma estimativa do tempo até a falência de um banco.

Minuzzi (2001) também construiu um modelo de previsão de descontinuidade, porém, através de regressão logística. A amostra utilizada no trabalho de Minuzzi (2001) foi composta por 323 empresas industriais que operaram no mercado de câmbio no período 1997-2000.

Com o intuito de reduzir o grau de correlação entre as variáveis, Minuzzi (2001) realizou um teste estatístico com um total de 49 indicadores financeiros. Seus resultados indicam que a regressão logística apresenta vantagens sobre a análise discriminante, quando aplicada à previsão de falência.

Pode-se verificar que os estudos citados anteriormente utilizaram diferentes métodos para tentar prever a descontinuidade das empresas, contudo todos eles utilizam apenas de dados obtidos a partir dos números apresentados nos demonstrativos contábeis.

\subsection{ESTUDOS QUE UTILIZARAM RELATÓRIOS ANUAIS CORPORATIVOS}

Em seu estudo, Balata e Breton (2005) propõem que os demonstrativos contábeis não são as únicas e nem mesmo as mais importantes informações utilizadas pelos analistas de mercado atualmente, os relatórios da diretoria também são utilizados na hora de definir onde investir.

Evidências apontadas na pesquisa de Schipper (1991) sugerem que a divulgação narrativa discricionária em relatórios anuais é de grande importância mesmo para usuários hábeis, tais como os analistas financeiros que estão entre os usuários principais da informação de contabilidade financeira.

Rogers e Grant (1997 apud SMITH \& TAFFLER, 2000), por exemplo, em sua comparação detalhada do conteúdo dos relatórios anuais da companhia e de relatórios dos analistas de vendas concluem que as seções descritivas do relatório anual (a carta do presidente, a discussão e análise da gerência [MD\&A] etc.) fornecem quase duas vezes a quantidade de informação citada do que as indicações financeiras básicas. Em média, as seções narrativas dos relatórios anuais que eles estudaram continham não menos que 40 por cento da informação citada por seus analistas.

Smith e Taffler (1992) apresentaram uma associação entre o desempenho das empresas e suas divulgações discricionárias. Quando as empresas estão em situação favorável, as seções narrativas do relatório anual tendem a ser mais claras, porém, quando a situação está adversa, os relatórios descritivos tendem a ser mais omissos e obscuros.

Foi a partir dessa pesquisa de 1992, que os próprios Smith e Taffler desenvolveram, no ano 2000, um trabalho buscando prever as falências das empresas utilizando seus relatórios discricionários.

A base de dados utilizada por Smith e Taffler (2000) foi de empresas de capital aberto, listadas ou que estavam listadas na bolsa de valores da capital britânica. Inicialmente eles selecionaram 54 empresas falidas, essas empresas deveriam ser 
emparelhadas com outras do mesmo setor, porém, a dificuldade de conseguir as combinações reduziu o número de empresas falidas para 33, ou seja, a amostra total foi de 66 empresas.

Smith e Taffler (2000) propuseram dois modelos lineares, um objetivo, com a simples contagem de palavras nos textos dos relatórios anuais corporativos e outro, mais subjetivo, baseado na contagem de temas aparentes daqueles relatórios (nesse caso chamado de chairman statement).

Os modelos propostos por Smith e Taffler (2000) calculam um score para cada empresa, sendo que para classificá-las corretamente, o score das empresas falidas deveria ser negativo e das empresas financeiramente saudáveis deveria ser positivo.

Os índices de acerto desses modelos propostos por Smith e Taffler (2000) foram de 98\% no primeiro modelo (modelo objetivo) e de $95 \%$ no segundo modelo (modelo subjetivo), índices superiores a muitos modelos tradicionais que utilizam os números contábeis como base de dados para prever a descontinuidade das empresas.

Nessa mesma linha, Bryan (1997) pesquisou a associação entre o disclosure narrativo do relatório anual com o futuro financeiro e retornos das ações das empresas. 0 relatório descritivo utilizado por Bryan (1997) foi o MD\&A (Management Discussion and Analysis).

Bryan (1997) utilizou dados de 250 MD\&A correspondentes ao período encerrado de 1990. Os resultados obtidos apontam que os dados apresentados nos MD\&A são significativamente associados com o futuro das empresas, especialmente com seu primeiro ano subseqüente.

Bryan (1997) ressalta que existem exigências de publicação de certos assuntos (como perspectivas de investimentos e de resultados) no MD\&A por parte da SEC (Securities and Exchange Comission), ou seja, existe controle sobre o que e como se publica o MD\&A.

Esse aspecto diferencia o MD\&A do Relatório da Administração (RA) brasileiro, devido às exigências, principalmente, da fiscalização por parte da SEC no MD\&A, o que, apesar de existirem as regras, não ocorre no Brasil com o RA.

Bryan (1997) cita que a SEC exige que as empresas, através dos MD\&A, forneçam informações relevantes aos investidores, como discussão e análise dos resultados e operações, de sua liquidez, dos capitais aplicados, além de suas perspectivas futuras.

Contudo, Abrahamson e Amir (1996) fizeram pesquisa bastante semelhante à de Bryan (1997), porém utilizando com base de dados o relatório intitulado "president letter" (carta do presidente), exatamente por que esse relatório não possui nenhuma determinação ou fiscalização quanto sua publicação.

Abrahamson e Amir (1996) também procuraram verificar se os dados contidos nos president letter estavam associados com seu desempenho financeiro futuro e o preço futuro das ações da companhia. A base de dados utilizada por Abrahamson e Amir (1996) foi de mais de 1.000 relatórios compreendidos entre 1989 e 1990.

Os resultados obtidos por Abrahamson e Amir (1996), apesar de utilizarem relatórios anuais que não são "regulados e fiscalizados", foram similares aos encontrados por Bryan (1997), ou seja, existe associação entre as informações textuais apresentadas nos relatórios anuais (president letter) com o futuro financeiro e o preço futuro das ações da companhia, principalmente no primeiro ano após a publicação desses relatórios.

De acordo com as pesquisas de Bryan (1997) e Abrahamson e Amir (1996) o fato de ser ou não regulamentado e fiscalizado não elimina o poder preditivo das informações apresentadas nas seções narrativas dos relatórios anuais. 


\subsection{DIFERENÇAS CONJUNTURAIS E DE MERCADO}

Em um mundo cada vez mais globalizado, em que barreiras são derrubadas, as diferenças entre os mercados dos diversos países vêm sendo amplamente estudadas nos últimos anos, seja através da influência dos ajustes contábeis aos diferentes GAAP (COSTA, 2005; NASCIMENTO, 2006) ou através da replicação ou aplicação de modelos desenvolvidos em um mercado em outro (LOPES, 2002).

Uma das principais diferenças entre nações é o sistema legal ou jurídico, que se refere aos dois principais modelos legais: o direito consuetudinário (common-law) e o direito romano (code-law). Austrália, Canadá, Reino Unido e Estados Unidos são exemplos de países que utilizam direito consuetudinário. Brasil, França, Alemanha e Japão são exemplos dos que adotam o direito romano.

Nascimento (2006), em seu estudo, resume as principais diferenças, do ponto de vista contábil, dos sistemas legais, como se pode observar no quadro 1.

Quadro 1: Diferenças entre os sistemas legais

\begin{tabular}{|c|c|c|}
\hline Pontos & Common Law & Code-Law \\
\hline Regulamentação & 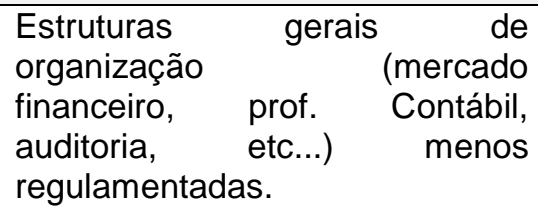 & \begin{tabular}{lrr} 
Estruturas & \multicolumn{2}{c}{ gerais } \\
organização & & (mercado \\
financeiro, prof. & Contábil, \\
auditoria, etc...) & mais \\
regulamentadas. &
\end{tabular} \\
\hline Estrutura Acionária & \begin{tabular}{llr} 
Estrutura & \multicolumn{2}{c}{ acionária dispersa } \\
entre um grande número de \\
acionistas. \\
System)
\end{tabular} & $\begin{array}{l}\text { Controle nas mãos de poucos } \\
\text { acionistas e ligados à gestão. } \\
\text { (Stakeholder System) }\end{array}$ \\
\hline $\begin{array}{l}\text { Força da Profissão } \\
\text { Contábil }\end{array}$ & $\begin{array}{l}\text { Auto regulamentadas e rom } \\
\text { enorme impacto social e } \\
\text { prestígio. }\end{array}$ & Não abordado. \\
\hline $\begin{array}{l}\text { Impacto Tributário } \\
\text { na } \\
\text { Contabilidade }\end{array}$ & $\begin{array}{l}\text { Pequena influência } \\
\text { legislação tributária }\end{array}$ & $\begin{array}{l}\text { Forte Interferência } \\
\text { legislação tributária. }\end{array}$ \\
\hline $\begin{array}{l}\text { Obrigatoriedade, } \\
\text { Pagt }^{\circ} \text { dividendos }\end{array}$ & Não abordado. & $\begin{array}{l}\text { Impacta sobre a "qualidade" } \\
\text { do lucro contábil. }\end{array}$ \\
\hline $\begin{array}{l}\text { Regulamentação } \\
\text { Contábil }\end{array}$ & $\begin{array}{l}\text { Está fora da esfera de } \\
\text { influência governamental. }\end{array}$ & $\begin{array}{l}\text { Normalmente regulada } \\
\text { legalmente diretamente pelo } \\
\text { governo. }\end{array}$ \\
\hline
\end{tabular}

Fonte: Nascimento (2006).

Além do sistema legal, outras diferenças separam o mercado brasileiro e o britânico no que se refere às divulgações contábeis, como, por exemplo, o idioma: enquanto na Inglaterra o idioma inglês tem origem anglo-saxônica, o português, idioma oficial do Brasil, é de origem latina.

Quanto à regulamentação contábil, segundo Lopes (2006), as diferenças também existem, como o tratamento das depreciações e P\&D, dentre outras. 
Os estudos de La Porta et al $(1997 ; 1998)$ pesquisaram o efeito de diferentes níveis legais de tratamento dado aos minoritários em diversos países e concluíram que essas diferenças estarão relacionadas com a grande diversidade encontrada em relação ao grau de concentração de propriedade das firmas, à política de dividendos praticada, ao acesso da firma a novas fontes de financiamento externo e ao desenvolvimento do mercado de capitais.

\subsection{OS MODELOS PROPOSTOS POR SMITH E TAFFLER (2000)}

Na literatura gerencial, Bettman e Weitz (1983), Staw et al. (1983), Salancik e Meindl (1984), Clapham e Schwenk (1991) e Abrahamson e Park (1994) adotam uma abordagem de análise de conteúdo para explorar as atribuições causais feitas pelas gerências da firma em seus relatórios descritivos para explicar ou esclarecer o desempenho da companhia. Os cinco estudos fornecem forte evidência de comportamento gerencial "em causa própria" ou "hedônica" na narrativa do relatório anual.

Tais atribuições em causa própria são uma tentativa de causar uma "impressão gerencial”, isto é, controlar as percepções da clientela interna e externa da firma sobre a firma para que haja a interação da maneira desejada.

Bowman (1984) usa o número de ocorrências da palavra "novo" do relatório da administração como uma medida do risco gerencial para apontar questões de risco e incerteza estratégicas da firma. Ele também enfatiza as vantagens da análise de conteúdo como uma medida reservada, desde que os relatórios sejam escritos para finalidades e públicos diferentes daqueles constituídas por analistas de conteúdo.

Estes estudos não olharam os casos em que as firmas beiravam a falência e estavam principalmente interessadas no processo de atribuição do gerenciamento causal. D'Aveni e MacMillan (1990) usam a análise de conteúdo dos relatórios anuais para analisar as respostas estratégicas diferenciais para demandar crises pelas gerências superiores de firmas falidas e subseqüentemente sobreviventes.

Frazier et al. (1984), McConnell et al. (1986), Swales (1988) e Yoon e Swales (1991), exploram se os dados qualitativos encontrados no relatório anual da firma podem prever o desempenho do preço da ação, usando a abordagem da análise de conteúdo para classificar e registrar temas recorrentes orientados para o futuro na carta do presidente. Yoon e Swales (1991) desenvolvem uma metodologia modelo de rede neural, uma questão explorada também por Abrahamson e Amir (1996).

Baseados nestes estudos, Smith e Taffler (2000) adotaram uma abordagem que envolve referências positivas e negativas e que permite a avaliação da importância de palavras e temas individuais. Os dois modelos desenvolvidos por Smith e Taffler (200) utilizaram técnicas multivariadas como a análise de discriminante linear, e os autores não impuseram limitações quanto ao seu uso em diferentes países.

Smith e Taffler (2000) utilizaram duas abordagens genéricas alternativas à análise de conteúdo: a análise orientada pela forma (objetiva), que envolve a contagem rotineira das palavras ou de referências concretas, e a análise orientada pelo significado (subjetiva), que foca na análise dos temas subjacentes dos textos estudados.

Para a construção dos modelos os autores inicialmente efetuaram um estudo piloto com 12 empresas, sendo seis "falidas" e seis "financeiramente saudáveis". Utilizaram uma combinação do programa de concordância de Oxford (OCP) com o software estatístico SPSS-X. 


\subsubsection{Modelo objetivo de Smith e Taffler}

No primeiro modelo multivariado de Smith e Taffler (2000), apresentado a seguir, a análise é mais objetiva e visa à busca de palavras chave dentro da análise do texto.

$Z=1,2+364,6($ PROF $)+1.005,0(E C O N)-557,8$ (CLOSE) $-6,4$ (NOMDIV) $-1.005,0$ (LEND)

$-2,8(B S)-718,9(R E C)$

Onde:

- PROF: (Lucro - Perda)

- ECON: Economia (melhora)

- REC: Recessão

- CLOSE: Fechamento (diminuição de vendas)

- NOMDIV: Redução de dividendos

- LEND: Empréstimos/dívidas

- BS: Apoio do Banco (financeiro)

Neste modelo, se o score $Z$ obtido for negativo é indício de que a empresa está passando por dificuldades financeiras (provável falência). Caso o score $Z$ seja positivo significa que a empresa está financeiramente "saudável".

As variáveis deste modelo foram geradas em um dicionário de análise de conteúdo, as variáveis compostas (por exemplo, lucro menos a perda) foram criadas também para finalidades analíticas. As variáveis da relação das palavras são derivadas assim:

Variável da palavra $=$

Número de ocorrências comuns

\section{Número total das palavras na narrativa}

As variáveis da palavra foram construídas usando esta fórmula para cada uma das palavras chave e seus compostos calculados rotineiramente para associações entre palavras específicas e o status financeiro das respectivas companhias.

Estes compostos são as variáveis formadas pela diferença entre a quantidade de palavras de mesmo significado como, por exemplo, o valor da variável PROF é determinado pela diferença entre a palavra lucro e seus sinônimos (lucrável, rentável, superávit etc.) menos a palavra perda (prejuízo, déficit etc.).

Neste contexto, o sentido da palavra é o mais importante, por isso a necessidade de contagem manual das palavras chave, por meio da leitura de cada um dos relatórios anuais, como por exemplo: "as oscilações do mercado fizeram com que a empresa não obtivesse lucro no período", nesse sentido a palavra lucro entra como redutora na variável PROF do modelo.

A composição das palavras chave que compõem cada uma das variáveis podem ser verificadas no dicionário apresentado no Apêndice I.

No início da construção desse modelo, Smith e Taffler (2000) chegaram a 36 palavras chave, sendo que a definição final sobre qual variável seria utilizada surgiu após verificação estatística para verificar quais teriam maior associação com a falência das empresas. 


\subsubsection{Modelo subjetivo de Smith e Taffler}

O segundo modelo proposto por Smith e Taffler (2000), apresentado a seguir, propicia uma análise de temas apresentados nos relatórios discricionários para chegar também ao score $Z$.

$$
Z=0,41+10,4 \text { (Boas Notícias) - 17,0(Más Notícias) - 14,5(Redução) }
$$

Onde:

Boas Notícias - desempenho positivo e notícia positiva sobre dividendos (Avaliativo: Benéfico)

Más Notícias - desempenho negativo e negativo e nenhuma notícia ou noticio ruim sobre dividendos (Avaliativo: Adverso)

Redução - redução das operações e/ou recessão na economia.

Da mesma forma que ocorre no primeiro modelo, se o score $Z$ for maior que zero, significa que a empresa está financeiramente saudável e, caso o score $Z$ for menor que zero, significa que a empresa passa por dificuldades financeiras (risco de falência).

Neste modelo, para cada frase da narrativa é designada uma contagem do tema e seu conteúdo temático estabelecido. A relação das variáveis é computada para a amostra principal das narrativas para cada tema na base de:

\section{Variável do tema $=$ Soma das frases com o tema

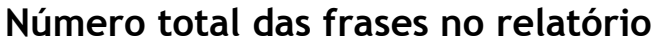

Caso se constate algum dos três temas descritos acima, o parágrafo é marcado e entra na contagem final dos parágrafos que mencionam o tema, ao final esse somatório é dividido pelo total de parágrafos da narrativa e esse resultado entra como variável do modelo.

\section{AMOSTRA}

Para chegar ao objetivo de testar os modelos apresentados, foram selecionadas empresas listadas na Bolsa de Valores de São Paulo (BOVESPA) com falências ou concordatas decretadas e emparelhadas com empresas do mesmo setor que se apresentem, até a presente data, financeiramente saudáveis.

Devido à dificuldade de obter um relatório contendo as empresas listadas na Bovespa que tiveram falência ou concordata decretada, a seleção da amostra passou por três etapas:

- Primeiramente foram selecionadas, no site da Bolsa de Valores de São Paulo, as empresas que tiveram seu registro cancelado, que montavam mais de duas mil empresas a partir do ano 2000. A grande maioria delas simplesmente fechou o capital ou foram incorporadas por outras empresas. Para selecionar as falidas ou concordatárias, através de consultas aos relatórios simplificados de cada uma dessas mais de duas mil empresas, separou-se as que tiveram seu registro cancelado por falta de atualização de informações. 
- Na seqüência, foram efetuadas consultas aos sites das empresas, ao site do jornal "Valor Econômico" (todas as edições do jornal a partir do ano 2000, na seção falências decretadas), ao site da Receita Federal, dentre outras fontes, para identificar as empresas que realmente entraram em concordata ou falidas, e o ano em que isso ocorreu.

* A partir do momento em que se identificaram as empresas falidas ou concordatárias, consultou-se o site da CVM para verificar se essas empresas possuíam dados disponíveis para a realização do trabalho, além de verificar a existência de outra empresa do mesmo setor também com dados disponíveis na CVM, devido à necessidade de formar pares entre "falidas" e "não falidas".

Formados os pares de empresas falidas (ou concordatárias) e não falidas, aplicaramse os modelos propostos por Smith e Taffler (2000) pelos quais se buscou verificar se, no Brasil, os resultados da análise de relatórios da administração como fonte de informações capaz de prever concordata (ou falência) são tão eficazes quanto na Inglaterra, tendo em vista as diferenças culturais, de idioma, da legislação e do uso contábil e da eficiência do mercado de capitais.

\section{MÉTODOS}

Em mercados mais desenvolvidos, conforme Smith e Tafler (2000), Bryan (1997) e Abrahanson e Amir (1996) é possível que a falência, ou o desempenho futuro das empresas baseados em seus relatórios anuais, sejam os relatórios fiscalizados quanto à sua publicação ou não.

No que diz respeito aos números contábeis, diversos autores já replicaram ou aplicaram conceitos e modelos desenvolvidos no mercado americano ou no mercado europeu, no Brasil, como Lopes (2002) e Rocha (1999), contudo, no caso de estudos com relatórios anuais, a menor fiscalização e regulação podem influenciar os resultados.

Considerando que o Brasil é um mercado completamente diferente do britânico, tanto no que diz respeito ao desenvolvimento, regulação das normas contábeis, idioma, cultura, dentre outros, este trabalho objetiva pesquisar se modelos desenvolvidos no mercado britânico, que buscam prever a falência das empresas, podem ser aplicados no Brasil.

Com base nos estudos de Bryan (1997) e Abrahanson e Amir (1996), que analisaram diferentes relatórios e chegaram praticamente às mesmas conclusões, e considerando que existem fatores que influenciam na divulgação dos relatórios contábeis que independem do mercado, espera-se que os resultados obtidos no Brasil sejam semelhantes aos obtidos em Londres.

Os procedimentos desta pesquisa partem da aplicação dos modelos em empresas brasileiras listadas na BOVESPA. Foram utilizados trinta relatórios anuais corporativos, sendo quinze de empresas que faliram e quinze de empresas que não faliram.

Como os dois modelos propostos por Smith e Taffler são classificatórios, ou seja, calculam uma "nota" e para classificar as empresas como "falidas" (nota menos que 0) e "não falidas" (nota maior que 0) utilizou-se o teste estatístico "t", com fórmula extraída de Hair et all (2005) para verificar se o poder de classificação dos modelos é estatisticamente significante.

Para aplicar o modelo objetivo de Smith e Taffler (2000), para cada variável da palavra (ou variável composta como lucro menos perda) foram contadas as palavras chave 
constantes nos relatórios anuais e essa soma foi dividida pela quantidade total de palavras do texto, após a divisão o resultado foi incluído na fórmula linear desenvolvida por Smith e Taffler (2000).

A relação da contagem de palavras para cada variável da palavra consta no Apêndice I. Verifica-se também que a variável "nomdiv" não teve influência no resultado final em nenhum dos relatórios.

Para a aplicação do segundo modelo de Smith e Taffler (2000), que calcula o score por meio dos temas aparentes dos relatórios anuais, os parágrafos foram identificados como trazendo "boas notícias", "más notícias" ou "redução/recessão".

A soma dos parágrafos da dissertativa que trazia as "boas notícias", as "más notícias" e que falavam sobre "redução/ recessão" foram divididos pela quantidade de parágrafos da narrativa e seu resultado lançado no modelo.

Como exemplo de tema/parágrafo que traz boas notícias exemplifica-se:

“A TAM obteve lucro de R\$ 174 milhões no exercício, um dos maiores já registrados pela companhia. Esse resultado é fruto de um trabalho consciente com alto grau de profissionalização que vem sendo desenvolvido ao longo dos últimos anos" (Trecho do Relatório da Administração da Cia Aérea TAM, referente ao exercício de 2003).

Como exemplo de tema/parágrafo que traz más notícias exemplifica-se:

“Devemos comentar também que ocorreu no período uma redução de preços médios de uma forma geral em virtude de uma acirrada concorrência em que o aumento das despesas operacionais com feiras e exposições contribuiu com a ocorrência de uma performance negativa" (Trecho do Relatório da Administração da Fechaduras Brasil S/A, referente ao exercício de 2000).

Como exemplo de tema/parágrafo que trata de redução das atividades ou recessão exemplifica-se:

“A redução da atividade no último trimestre e, principalmente, as altas taxas de juros, que afetaram os passivos fiscal e bancário, foram as causas do prejuízo do exercício". (Trecho do Relatório da Administração da Construtora Coest S/A, referente ao exercício de 1997).

Como critério de análise, um mesmo parágrafo não pode ser computado como má notícia e como redução/recessão ao mesmo tempo.

O mapa da contagem dos parágrafos em cada empresa pode ser visualizado no Apêndice III.

\section{RESULTADOS}

Foi utilizada uma amostra com 30 observações (relatórios), referentes a 28 empresas (Coteminas e Tam aparecem com dois relatórios em anos diferentes), sendo quinze com falências decretadas e quinze financeiramente saudáveis para chegar a resultados de aplicabilidade dos modelos. tabela 1:

As empresas da amostra e o ano dos relatórios utilizados estão apresentados na 
Quadro 3: Empresas e ano do relatório utilizadas no estudo

\begin{tabular}{|c|c|c|}
\hline EMPRESAS FALIDAS & EMPRESAS NÃO FALIDAS & ANO DO RELATORIO ANUAL \\
\hline BANCO CREFISUL & BANCO MERCANTIL & 1998 \\
\hline CASA ANGLO BRASILEIRA & LOJAS RENNER & 1997 \\
\hline TRANSBRASIL & TAM & 1999 \\
\hline CIA ITAUNENSE & CONF. GUARARAPES & 1997 \\
\hline CIA LORENZ & JOSAPAR & 1997 \\
\hline KALIL SEHBE & COTEMINAS & 1997 \\
\hline BRASPÉROLA & COTEMINAS & 1999 \\
\hline VASP & TAM & 2003 \\
\hline IMPÉRIO LISAMAR & CONSERVAS ODERICH & 1997 \\
\hline CIA PAULISTA & FOSFÉRTIL & 1997 \\
\hline ELEBRA & SPRINGER & 1999 \\
\hline SHARP & GRADIENTE & 1998 \\
\hline CNV & STAROUP & 1997 \\
\hline COEST & AZEVEDOS E TRAVASSOS & 1997 \\
\hline FECHADURAS BRASIL & GERDAU & 2000
\end{tabular}

\subsection{RESULTADOS APLICANDO O MODELO OBJETIVO DE SMITH E TAFFLER}

Aplicando o primeiro modelo proposto por Smith e Taffler (2000) chegou-se aos resultados ( $\mathrm{Z}$ - Score) apresentados na tabela 2:

Com a utilização desse modelo, o índice de acerto foi de $90 \%$, sendo que os erros (Casa Anglo Brasileira, Banco Crefisul e VASP) foram de empresas que "quebraram" e foram classificadas com o Score positivo.

Tabela 1: Resultados com a utilização do primeiro modelo

\begin{tabular}{|c|c|c|c|}
\hline EMPRESA & SCORE $\boldsymbol{Z}$ & EMPRESA & SCORE $\boldsymbol{Z}$ \\
\hline CASA ANGLO BRASILEIRA* & 1,90 & RENNER & 2,42 \\
\hline TRANSBRASIL & $-1,08$ & TAM & 1,24 \\
\hline BCO CREFISUL* & 1,02 & BCO MERCANTIL & 1,64 \\
\hline CIA ITAUNENSE & $-3,37$ & CONF GUARARAPES & 2,02 \\
\hline CIA LORENZ & $-1,42$ & JOSAPAR & 0,34 \\
\hline KALIL SEHBE & $-7,60$ & COTEMINAS & 0,87 \\
\hline BRASPÉROLA & $-4,16$ & COTEMINAS & 1,85 \\
\hline VASP* & 1,10 & TAM & 1,32 \\
\hline IMPERIO LISAMAR & $-4,44$ & CONSERVAS ODERICH & 2,82 \\
\hline CIA PAULISTA & $-2,12$ & FOSFÉRTIL & 1,52 \\
\hline ELEBRA & $-0,94$ & SPRINGER & 1,78 \\
\hline SHARP & $-1,55$ & GRADIENTE & 2,11 \\
\hline CNV & $-0,29$ & STAROUP & 0,78 \\
\hline COEST & $-1,85$ & AZEVEDO E TRAVASSOS & 0,13 \\
\hline FECHADURAS BRASIL & $-1,32$ & GERDAU & 0,87 \\
\hline
\end{tabular}

*Empresas classificadas erroneamente 
Esses resultados corroboram os estudos de Bryan (1997) e Abrahanson e Amir (1996) no sentido de que as informações apresentadas nos relatório anuais permitem a realização de inferências sobre o desempenho futuro da firma. Também se sugere que os resultados obtidos corroboram a teoria da divulgação, já que não houve diferença entre esses resultados e os obtidos em Londres por Smith e Taffler (2000).

\subsection{RESULTADOS APLICANDO O MODELO SUBJETIVIO DE SMITH E TAFFLER}

Utilizando o segundo modelo, que analisa os temas propostos, os resultados foram os apresentados na tabela 3.

Com esse modelo o índice de acerto foi de $96 \%$, com o erro de classificação sendo também de uma empresa falida (Casa Anglo) como não falida, como pode ser visualizado na Tabela 2.

Tabela 2: Resultados com a utilização do segundo modelo

\begin{tabular}{|c|c|c|c|}
\hline EMPRESA & SCORE $\boldsymbol{Z}$ & EMPRESA & SCORE $\boldsymbol{Z}$ \\
\hline CASA ANGLO* & 0,81 & RENNER & 1,28 \\
\hline TRANSBRASIL & $-3,22$ & TAM & 0,26 \\
\hline BCO CREFISUL & $-0,19$ & BCO MERCANTIL & 0,11 \\
\hline CIA ITAUNENSE & $-4,84$ & CONF GUARARAPES & 1,57 \\
\hline CIA LORENZ & $-0,70$ & JOSAPAR & 0,41 \\
\hline KALIL SEHBE & $-6,19$ & COTEMINAS & 0,99 \\
\hline BRASPÉROLA & $-0,53$ & COTEMINAS & 2,32 \\
\hline VASP & $-0,76$ & TAM & 0,98 \\
\hline IMPÉRIO LISAMAR & $-8,95$ & CONSERCAS & 7,34 \\
\hline CIA PAULISTA & $-3,27$ & ODERICH & 2,79 \\
\hline ELEBRA & $-6,39$ & FOSFÉRTIL & 1,91 \\
\hline SHARP & $-3,88$ & GRANGER & 3,88 \\
\hline CNV & $-2,99$ & STAROUP & 1,21 \\
\hline COEST & $-1,66$ & AZEVEDO E & 0,39 \\
\hline FECHADURAS BRASIL & $-7,15$ & TRAVASSOS & 2,94 \\
\hline
\end{tabular}

*Empresa classificada erroneamente

\section{CONCLUSÃO}

O objetivo deste trabalho foi verificar a aplicabilidade dos modelos preditivos de Smith e Taffler (2000) no mercado brasileiro. Os índices de acerto na classificação de empresas falidas e não falidas, apurados pelos modelos desenvolvidos por Smith e Taffler (2000), quando aplicados ao mercado brasileiro, mais especificamente nesta amostra extraída de empresas listadas na BOVESPA, aliados aos testes estatísticos que permitem verificar se o poder de classificação dos modelos é estatisticamente significativo permite concluir que é possível prever a descontinuidade das empresas, com base nas informações obtidas nos relatórios anuais corporativos, ou seja, os modelos desenvolvidos por Smith e Taffler (2000) puderam ser aplicados nesta amostra sem alterações significativas em seu poder preditivo. 
Percebe-se também que os resultados em muito se assemelham aos obtidos quando os modelos foram aplicados em Londres, ou seja, especificamente em relação aos mercados inglês e brasileiro as diferenças conjunturais de cada nação não interferiram significativamente na aplicabilidade dos modelos.

No que diz respeito ao poder de classificação dos modelos, verificou-se que o índice de acerto na classificação é estatisticamente significante a $1 \%(\mathrm{t}=4,38)$ no primeiro modelo e também é significativo a $1 \%(t=5,11)$ no segundo modelo, o mesmo índice obtido em Londres.

Apesar de os relatórios anuais não serem muito utilizados com o intuito de prever a falência das firmas, os resultados da aplicação dos modelos desenvolvidos por Smith e Taffler (2000) demonstram que uma combinação das palavras chave e dos temas subjacentes presentes nas seções narrativas dos relatórios anuais corporativos permitem um grau elevado de discriminação de firmas falidas e não falidas.

Estes resultados corroboram os estudos de Frazier e outros (1984), McConnell e outros (1986), Swales (1988) e Yoon e Swales (1991), Abrahanson e Amir (1996), Bryan (1997) e dos próprios Smith e Taffler (2000) no sentido de que os dados contidos nos relatórios anuais corporativos são importantes fontes de informação para se prever o desempenho futuro das firmas.

Assim como as evidências apontadas na pesquisa de Schipper (1991) e de Rogers e Grant (1997) apud Smith e Taffler 2000, que sugerem que a divulgação narrativa discricionária em relatórios anuais é de grande importância para analistas financeiros, este estudo indica um caminho que deve ser mais explorado no Brasil, tanto internamente na firma, que deve analisar melhor o que está divulgando em suas seções narrativas, como para o mercado, que pode utilizar mais esta importante ferramenta para quebra da assimetria informacional.

Durante a realização da pesquisa bibliográfica e empírica, foi possível constatar algumas importantes limitações deste estudo:

- Amostra: Devido à dificuldade de obtenção de dados e formação de pares entre empresas falidas e não falidas, a amostra deste estudo foi composta por apenas 30 relatórios e os resultados e as conclusões estão restritos à amostra selecionada.

- Modelos Utilizados: Os modelos utilizados foram desenvolvidos no mercado londrino e, devido à restrição da amostra que impossibilitou a criação de uma pré-amostra para análise preliminar, sem qualquer adaptação para o mercado brasileiro.

- Procedimentos: Os procedimentos utilizados para a pesquisa foram similares aos utilizados por Smith e Tafler (2000) após a criação dos modelos e, assim como o modelo original está sujeito a erros de classificação do pesquisador.

\section{REFERÊNCIAS}

ABRAHAMSON, E.; AMIR, E.. The information content of the president's letter to shareholders. Journal of Business Finence \& Accounting, v. 23, 8, 1996.

ABRAHANSON, E.; PARK, C. Concealment of negative organizational outcomes: an agency theory perspective. Academy of Management Journal, v. 37, 5, p. 1302-1334, 1994.

ALTMAN, Edward I. Financial Ratios, Discriminant Analysis and Fite Prediction Of Corporate Bankruptcy. Journal of Finance, v. 23, 4, 1968. 
BALATA, P.; BRETON, G. Narratives vs Nunbers in Anual Report. Review of Accounting \& Finance, v. 4, 2, 2005.

BALL, R.; FOSTER, G. Corporate Financial Reporting: A Methodological Review of Empirical Research. Journal of Accounting Research, v. 20, 1982.

BEAVER, W. H. Alternative Accouting Measures As Predictors of Failure. The Accounting Review, v. 43, 1, p. 113-122, 1968.

BETTMAN, J.R. and WEITZ, B.A. Attributions in the board room: causal reasoning in corporate annual reports. Administrative Science Quarterly, v. 28, p. 165-83,1983.

BOVESPA, Dados de Companhias Abertas. Disponível em <<http://www.bovespa.com.br $>>$. Acesso em 15 ago. 2007.

BOWMAN, E. H. Content analysis of annual reports for corporate strategy and risk. Interfaces, v. 14, January-February, p. 61-71, 1984.

BRASIL. Lei $n^{\circ} 11.101$, de 9 de fevereiro DE 2005. Dispõe sobre a recuperação judicial. Diário Oficial da República Federativa do Brasil, Brasília, 10 fev. de 2005. Disponível em: «www.in.gov.br». Acesso em 02 nov. 2007.

BRETON, G.; TAFFLER, R. J. Accounting information and analyst stock recommendation decisions: a content analysis approach. Accounting and Business Review, v. 31, 2, p. 91 101, 2001.

BRYAN, S. H. Incremental Information Content of Required Disclosures in Management Discussion and Analysis. The Accounting Review, v. 72, 2, 1997.

BUSHMAN, R. M. and PIOTROSKI, J. D. Financial reporting incentives for conservative accounting: The influence of legal and political institutions. Forthcoming Journal of Accounting and Economics, January 2005. Disponível em <http://papers.ssrn.com/> Acesso em 15 mar. 2008.

CLAPHAM, S. E. and SCHWENK, C. R. Self-serving attributions, managerial congnition and company performance, Strategic Management Journal, v. 12, p. 219-229, 1991.

COELHO, F. U. Manual de Direito Comercial. 17.ed. São Paulo, Saraiva, 2006.

COSTA, F. M. Ajustes aos US-GAAP: Estudo Empírico sobre sua relevância para empresas brasileiras com ADRs negociadas na bolsa de Nova lorque. São Paulo: 2005, 139f. Tese (Doutorado em Controladoria e Contabilidade). São Paulo - Faculdade de Economia, Administração e Contabilidade, Universidade de São Paulo, São Paulo.

COX, D. R. Regression Models And Life-Tables. Journal of The Royal Statistic Society. "B” Series, 34, 1972, p.187-220.

CVM, Relatórios da Administração. Disponível em <<http://www.cvm.gov.br >>. Acesso em 1 set. 2007.

D'AVENI, R. A.; MACMILLAN, I. C. Crisis and the content of managerial communications: a study of the focus of attention of top managers in surviving and failing firms. Administrative Science Quarterly, v. 35, 1990, p. 634-57.

FRAZIER, K. B.; INGRAN, R. W.; TENNISON, M. B. A Methodology for the Analysis of Narrative Accounting Disclosures. Journal of Accounting Research, v. 22, 1, 1984.

HAIR, J.F.; ANDERSON, R. E.; TATHAM, R.L.; BLACK, W.C. Análise Multivariada de Dados. 5.ed. Porto Alegre: Bookman, 2005.

HENDRIKSEN, E. S; VAN BREDA, M. Teoria da Contabilidade. 5.ed., Atlas, São Paulo 1999.

KANITZ, S. C. Como prever Falências. Exame. São Paulo: Abril, dez. 1974. 
LA PORTA, R.; LOPES-DE-SILANES, F.; SHLEIFER, A.; VISHNY, R. Legal Determinants of External Finance. The Journal of Finance, v. 52, 3, p. 1131-1150, 1997.

1998. . Law and Finance. The Journal of Political Economy, v. 106, 6, p.1113-1155,

LENNOX, C. Identifying Failing Companies: A Re-evaluation of the Logit, Probit, and DA Approaches, Journal of Economics and Business, 51, p. 347-364, 1999.

LOPES, A. B. Uma contribuição ao Estudo da Relevância da Informação Contábil para o Mercado de Capitais: 0 modelo de Ohlson Aplicado à BOVESPA. São Paulo: 2001, 308f. Tese (Doutorado em Controladoria e Contabilidade) - Departamento de Contabilidade e Atuaria, Faculdade de Economia, Administração e Contabilidade, Universidade de São Paulo, São Paulo.

2002.

A informação contábil e o mercado de capitais, 1.ed. São Paulo: Thompson.

Empirical Evidence on the Relation Between Revaluations of Fixed Asset and Future Firm Performance in Brazil. In: GREGORIUS, G.; GRABER, M. (Org.) International Accounting: Standards, Regulations and Financial Reporting. Elsevier, 2006.

MATIAS, A. B.; SIQUEIRA, J. O. Risco Bancário: Modelo de Previsão de Insolvência de Bancos no Brasil. Revista de Administração, São Paulo, v. 31, 2, p.19-28, abr. -jun., 1996.

MCCONNELL, D., HASLEM, J. A.; GIBSON, V. R. The president's letter to stockholders: a new look. Financial Analysts Journal, pp. 66-70, Sept. - Oct., 1986.

MINUSSI, J. A. Modelo Preditivo de Solvência Utilizando Regressão Logística. Rio de Janeiro: 2001, 150f. Dissertação (Mestrado em Administração) - Departamento de Administração de Empresas, Pontifícia Universidade Católica, Rio de Janeiro, 2001.

MORRIS, Richard D.; Signalling. Agency Theory and Accounting Choice, Accounting and Bussiness Research, v. 18, 69, p. 47-56, 1987.

NASCIMENTO, M. Análise do Conteúdo Informacional do Resultado Contábil em US-GAAP: um estudo de evento em companhias abertas que negociam ADR's na bolsa de Nova lorque. Vitória: 2006, 103f. Dissertação (Mestrado em Contabilidade) - FUCAPE Business School, Vitória.

ROCHA, F. Previsão de Falência Bancária: Um Modelo de Risco Proporcional. Pesquisa e Planejamento Econômico, Rio de Janeiro, v.29, 1, p. 137-152, abr. 1999.

SALANCIK, G. R.; MEINDL, J. R. Corporate attributions as strategic illusions of management control. Administrative Science Quarterly, v. 29, p. 238-254, 1984.

SILVA, C. A. T.; RODRIGUES, F. F.; ABREU, R. L. Análise dos Relatórios da Administração das Companhias Abertas Brasileiras: Um Estudo do Exercício Social de 2002, RAC, v. 11, 2, p. 71-92, 2007.

SKINNER, D. J. Why Firms Voluntarily Disclosure Bad News. Journal of Accouting Research. USA, v. 32, 1, 1994.

SMITH, M.; TAFFLER, R. J. The Chairman's Statement. Accounting Auditing \& Accountability Journal, v. 13, 5, 2000.

SRF. Secretaria da Receita Federal. Consulta situação cadastral do CNPJ. Disponível em «http://www.receita.fazenda.gov.br». Acesso em 2 set. 2007.

SWALES, G. S. Another look at the president's letter to stockholders. Financial Analysts Journal, p. 71-73, Mar. - Apr., 1988. 
YOON, Y.; SWALES, G. Predicting stock price performance: a neural network approach. Proceedings of the IEEE 24th Annual International Conference of Systems Sciences, January, p. 156-162, 1991.

\section{ENDEREÇO DOS AUTORES}

Fundação Instituto Capixaba de Pesquisa em

Contabilidade, Economia e Finanças

Av. Fernando Ferrari, 1358 - Boa Vista

Vitoria, ES - Brasil

29075-505 


\section{APÊNDICE I: Dicionário dos sinônimos utilizados para cada variável do primeiro modelo}

\begin{tabular}{|c|c|c|}
\hline Variável & Palavras que somam no resultado & $\begin{array}{l}\text { Palavras que diminuem no } \\
\text { resultado }\end{array}$ \\
\hline PROF & $\begin{array}{l}\text { Lucro, Lucrável, Lucrativa, Rentável, } \\
\text { Superávit }\end{array}$ & $\begin{array}{l}\text { Perda, Prejuízo, Redução do } \\
\text { Lucro, Déficit }\end{array}$ \\
\hline ECON & Economia (melhora) & Economia (piora) \\
\hline CLOSE & $\begin{array}{l}\text { Redução das atividades, fechamento, } \\
\text { redução de vendas }\end{array}$ & \\
\hline NOMDIV & $\begin{array}{l}\text { Sem dividendos, Dividendo nominal, } \\
\text { Dividendo reduzido }\end{array}$ & Dividendo aumentado \\
\hline LEND & Débitos, Dívidas, Empréstimos & \\
\hline $\mathrm{BS}$ & $\begin{array}{l}\text { Apoio do banco, concessão de } \\
\text { empréstimos }\end{array}$ & \\
\hline REC & Recessão & \\
\hline
\end{tabular}




\section{APÊNDICE II: Dados que geraram os resultados do primeiro modelo}

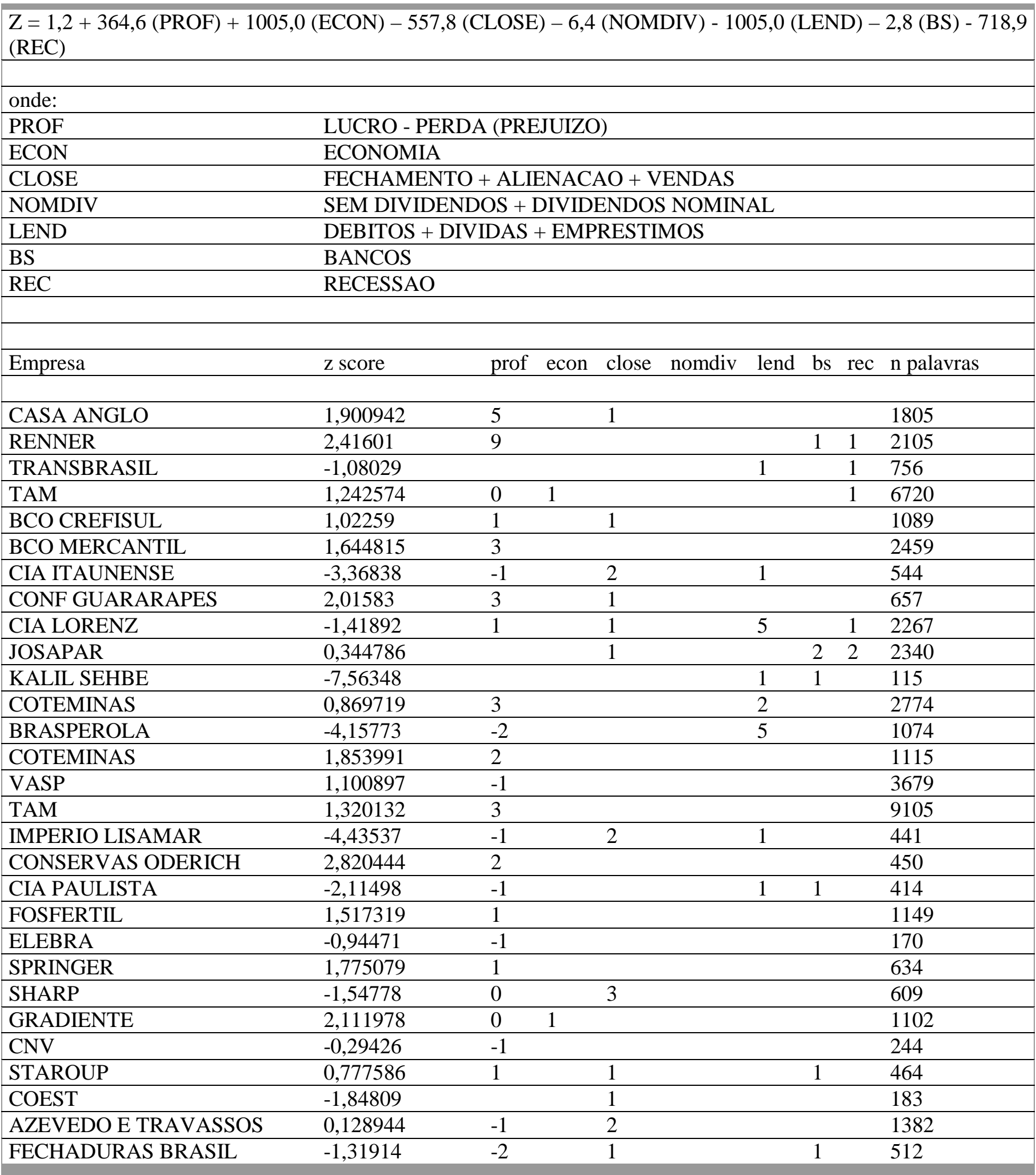




\section{APÊNDICE III: Dados que geraram os resultados do segundo modelo}

\begin{tabular}{|c|c|c|c|c|c|}
\hline Empresa & Z Score & boas & mas & reducao/recessao & $\mathrm{n}$ paragrafos \\
\hline CASA ANGLO & 0,81 & 1 & & & 26 \\
\hline RENNER & 1,276666667 & 1 & & & 12 \\
\hline TRANSBRASIL & $-3,215$ & & & 1 & 4 \\
\hline TAM & 0,26 & 1 & & 2 & 124 \\
\hline BCO CREFISUL & $-0,194166667$ & & & 1 & 24 \\
\hline BCO MERCANTIL & 0,107916667 & & & 1 & 48 \\
\hline CIA ITAUNENSE & $-4,84$ & & 1 & 1 & 6 \\
\hline CONF GUARARAPES & 1,565555556 & 1 & & & 9 \\
\hline CIA LORENZ & $-0,700526316$ & 1 & 1 & 1 & 19 \\
\hline JOSAPAR & 0,41 & & & & 16 \\
\hline KALIL SEHBE & $-6,19$ & 1 & 1 & & 1 \\
\hline COTEMINAS & 0,993018868 & 6 & 1 & 1 & 53 \\
\hline BRASPEROLA & $-0,532857143$ & 2 & 2 & & 14 \\
\hline COTEMINAS & 2,324814815 & 8 & 1 & 1 & 27 \\
\hline VASP & $-0,762222222$ & 1 & 1 & 1 & 18 \\
\hline TAM & 0,980689655 & 8 & 1 & & 116 \\
\hline IMPERIO LISAMAR & $-8,947142857$ & & 3 & 1 & 7 \\
\hline CONSERVAS ODERICH & 7,343333333 & 4 & & & 6 \\
\hline CIA PAULISTA & $-3,27$ & 3 & 4 & & 10 \\
\hline FOSFERTIL & 2,787142857 & 8 & & & 35 \\
\hline ELEBRA & $-6,39$ & & 2 & & 5 \\
\hline SPRINGER & 1,91 & 5 & 2 & & 12 \\
\hline SHARP & $-3,880909091$ & 2 & 4 & & 11 \\
\hline GRADIENTE & 3,876666667 & 5 & & & 15 \\
\hline $\mathrm{CNV}$ & $-2,99$ & & 1 & & 5 \\
\hline STAROUP & 1,21 & 1 & & & 13 \\
\hline COEST & $-1,661428571$ & & & 1 & 7 \\
\hline $\begin{array}{l}\text { AZEVEDO E } \\
\text { TRAVASSOS }\end{array}$ & 0,385 & 3 & 1 & 1 & 12 \\
\hline FECHADURAS BRASIL & $-7,145555556$ & & 4 & & 9 \\
\hline GUERDAU & 2,93972973 & 9 & & & 37 \\
\hline
\end{tabular}

